\title{
Demographic, clinical, and functional determinants of antithrombotic treatment in patients with nonvalvular atrial fibrillation
}

Jose María Mostaza ${ }^{1 *} \mathbb{D}$, Carmen Suarez ${ }^{2}$, Jose María Cepeda ${ }^{3}$, Luis Manzano ${ }^{4}$, Demetrio Sánchez ${ }^{5}$ and on behalf of the PERFILAR study investigators

\begin{abstract}
Background: This study assessed the sociodemographic, functional, and clinical determinants of antithrombotic treatment in patients with nonvalvular atrial fibrillation (NVAF) attended in the internal medicine setting.

Methods: A multicenter, cross-sectional study was conducted in NVAF patients who attended internal medicine departments for either a routine visit (outpatients) or hospitalization (inpatients).

Results: A total of 961 patients were evaluated. Their antithrombotic management included: no treatment (4.7\%), vitamin K antagonists (VKAs) (59.6\%), direct oral anticoagulants (DOACs) (21.6\%), antiplatelets (6.6\%), and antiplatelets plus anticoagulants (7.5\%). Permanent NVAF and congestive heart failure were associated with preferential use of oral anticoagulation over antiplatelets, while intermediate-to high-mortality risk according to the PROFUND index was associated with a higher likelihood of using antiplatelet therapy instead of oral anticoagulation. Longer disease duration and institutionalization were identified as determinants of VKA use over DOACs. Female gender, higher education, and having suffered a stroke determined a preferential use of DOACs.

Conclusions: This real-world study showed that most elderly NVAF patients received oral anticoagulation, mainly VKAs, while DOACs remained underused. Antiplatelets were still offered to a proportion of patients. Longer duration of NVAF and institutionalization were identified as determinants of VKA use over DOACs. A poor prognosis according to the PROFUND index was identified as a factor preventing the use of oral anticoagulation.
\end{abstract}

Keywords: Antithrombotic treatment, Direct-acting oral anticoagulants (DOACs), Nonvalvular atrial fibrillation (NVAF), Vitamin K antagonists (VKAs)

\section{Background}

Atrial fibrillation (AF) is the most common type of sustained cardiac arrhythmia, and its prevalence rises with age, with about $18 \%$ of patients older than 80 years being affected [1]. Nonvalvular AF (NVAF) is strongly associated with increased morbidity and mortality related to

\footnotetext{
*Correspondence: josemaria.mostaza@salud.madrid.org

1 Department of Internal Medicine, Hospital Carlos III, Calle Sinesio

Delgado, 10, 28029 Madrid, Spain

Full list of author information is available at the end of the article
}

ischemic stroke and systemic thromboembolism $[2,3]$. The risk of stroke in AF patients is about fivefold higher than in the non-AF population [4], and AF-related strokes are generally more severe, with increased risk of death and disability compared to strokes from other causes [5]. Elderly patients with AF are at higher risk of stroke than younger AF patients [6,7]. Indeed, age $\geq 75$ years is a significant risk factor comparable to a history of stroke for the assessment of stroke risk by the $\mathrm{CHA}_{2} \mathrm{DS}_{2}$-VASc score [8]. Prevention of stroke is therefore imperative in AF patients, particularly in elderly patients. 
Oral anticoagulation (OAC) with vitamin $\mathrm{K}$ antagonists (VKA) has traditionally been the mainstay for stroke prevention in AF based on the robust clinical evidence of their efficacy in preventing stroke or systemic embolism and reducing mortality [9]. However, VKAs have several known limitations, including the risk of major bleeding complications, especially intracranial hemorrhage, many food and drug interactions, and the need for frequent coagulation monitoring due to their narrow therapeutic window. Direct-acting oral anticoagulants (DOACs) targeting thrombin or factor Xa emerged as a welcome addition for stroke prevention in AF. These agents have predictable pharmacodynamic effects, allowing fixed dosing without the need for anticoagulation monitoring [10]. DOACs, such as rivaroxaban, dabigatran, apixaban and edoxaban, have demonstrated to be noninferior to warfarin in stroke prevention without an increased risk of major bleeding [11-15]. Based on their favorable efficacy, safety profile and convenience of use, DOACs are recommended over VKAs for stroke prevention in most patients with NVAF [16].

Adequate selection of antithrombotic therapy for stroke prevention is critical for improving the clinical outcome of patients with NVAF. Several clinical practice guidelines have been developed to guide the management of AF patients, providing clinicians with recommendations on individualization of treatment based on the patient's characteristics $[16,17]$. However, the implementation of guideline recommendations in routine clinical practice may be suboptimal. OAC is still underused in AF patients who are at high risk of stroke, and many patients are instead treated with antiplatelet agents or do not receive antithrombotic treatment $[18,19]$. Accordingly, despite the higher risk of stroke and bleeding in elderly NVAF patients [20], anticoagulation has been traditionally underused in this population mainly due to the high frequency of associated comorbidities, including cardiovascular and kidney disease, multiple drug therapy, and concerns about cognitive impairment and risk of falls and bleeding [21].

To date, limited data are available on the clinical management of NVAF patients, particularly in those patients attended in the internal medicine setting, where these patients are typically managed. There is therefore a need to identify current therapies used for stroke prevention and the factors that may guide the selection of treatment in the real-world setting. A better understanding of treatment patterns and factors potentially influencing treatment strategy is crucial to know whether clinical practice is in line with treatment recommendations of the current guidelines. Knowledge about the clinical management of patients with NVAF in clinical practice may improve OAC utilization for stroke prevention and outcomes.
Based on this background, we conducted a cross-sectional study to describe the demographic, functional, and clinical characteristics of patients with NVAF attending internal medicine departments in Spanish hospitals and the potential factors associated with antithrombotic treatment patterns.

\section{Methods \\ Study design and patients}

A multicenter, cross-sectional observational study was conducted in internal medicine departments from 93 hospitals distributed across Spain.

Eligible patients were consecutive adult patients (aged $\geq 18$ years) diagnosed with NVAF (defined as the rhythm disturbance occurring in the absence of rheumatic mitral stenosis or a prosthetic heart valve) who attended the internal medicine departments either for a routine visit (outpatients) or hospitalization (inpatients) for any reason during the 9-month enrolment period. Patients were selected on the basis of the information recorded in the medical charts. The patients must have been diagnosed with NVAF before the study inclusion, and disease-related data (type of NVAF, disease duration, etc.) was collected from medical charts. Patients currently receiving anticoagulant therapy for venous thromboembolism and patients participating in a clinical trial with anticoagulant or antiplatelet agents in the previous six months were excluded.

A cross-sectional chart review was performed to collect patients' sociodemographic, functional and clinical data, as well as treatment-related data. The social, functional, and cognitive status of patients was also assessed through face-to-face interviews with patients at the time of the study visit (cross-sectional evaluation). Cognitive impairment was evaluated using the Pfeiffer questionnaire [22, 23], and data on functional disability assessed using the Barthel index [24] was collected. Patient comorbidity was measured by using the Charlson comorbidity index [25] (absent of comorbidity: score $=0-1$; low comorbidity: score $=2$; severe comorbidity: score $\geq 3$ ). The PROFUND index score [26] was calculated to estimate one-year mortality risk as follows: low-risk (12.1-14.6\%) for a score of $0-2$, low-intermediate risk (21.5-31.5\%) for a score of 3-6, intermediate-high risk (45-50\%) for a score of $7-10$, and high-risk $(61.3-68 \%)$ for a score $\geq 11$. Physician's estimation of the patient's life expectancy $(<6$ or $\geq 6$ months) was also assessed. The risk of ischemic stroke and bleeding was assessed by $\mathrm{CHA}_{2} \mathrm{DS}_{2}$-VASc score [8] and HAS-BLED score [27], respectively.

The independent ethics committee of La Princesa University Hospital (Madrid, Spain) approved the study. All patients gave their written informed consent before their inclusion in the study. The study was carried out in accordance with the 
Declaration of Helsinki and Good Clinical Practice Guidelines and applicable regulatory requirements.

\section{Statistical analysis}

In order to describe the demographic, functional, and clinical characteristics of patients on each antithrombotic treatment approach, patients included in the study were categorized into five groups according to the antithrombotic therapy used for their clinical management as follows: no treatment, VKAs (acenocumarol or warfarin), DOACs (apixaban, rivaroxaban or dabigatran), antiplatelet drugs (aspirin and/or other antiplatelets), and antiplatelet plus anticoagulant drugs. Only patients who fulfilled the eligibility criteria and could be categorized in any of these treatment groups were considered as evaluable for the study analysis. A descriptive analysis of the characteristics of each treatment group was performed using measures of central tendency and dispersion (mean $[ \pm$ standard deviation], median [interquartile range]) for quantitative variables, and counts and percentages for qualitative variables. The KolmogorovSmirnov test and the Shapiro-Wilk test were used for checking normality of data. The Kruskal-Wallis test was used to compare continuous non-parametric variables and the ANOVA to compare continuous parametric variables. The Chi-square or Fisher's exact test was used for comparison of categorical variables.

Stepwise binary logistic regression analyses were conducted to assess the potential factors associated with the use of specific treatment strategies whose comparison is of clinical relevance. Thus, factors associated with OAC (VKAs, DOACs, or any OAC plus antiplatelet therapy) versus antiplatelet therapy and with VKAs versus DOACs were assessed. Clinically relevant variables and those with a $p<0.2$ were included in each multivariate model with stepwise selection to determine independent factors associated with each treatment strategy used for clinical management. Odds ratio (OR) and 95\% confidence inter$\operatorname{val}(95 \% \mathrm{CI})$ were calculated.

All analyses were performed using the Statistical Package for the Social Sciences (SPSS) version 18.0 (SPSS Inc., Chicago, IL, USA).

\section{Results}

\section{Patients and treatment}

A total of 1000 patients from 93 hospitals distributed across Spain were enrolled in the study from March to October 2015. Thirteen patients were excluded from the analysis, as they did not meet at least one inclusion criteria. Therefore, a total of 987 patients were included in the study analysis. A total of 26 patients could not be categorized in any of the five treatment groups. As a result, 961 patients were evaluable for the study analysis (Fig. 1).
Most patients received antithrombotic treatment (>95\%). Overall, $88.7 \%$ of patients received OAC (VKAs, DOACs, or any OAC plus antiplatelet therapy). The majority of patients were treated with VKAs (nearly $60 \%$ of patients), and DOACs were received by less than onequarter of patients. Antiplatelet therapy alone was used in less than $7 \%$ of patients, and OAC plus antiplatelet therapy was received by nearly $8 \%$ of patients (Fig. 1 ).

\section{Demographic and functional characteristics, morbidity and life expectancy}

The demographic and functional characteristics, morbidity and life expectancy of patients according to the antithrombotic treatment strategy are shown in Table 1. The median age of patients was 81 years, with similar proportions of male and female patients. Most patients were not institutionalized $(>90 \%)$ and had no cognitive impairment according to the Pfeiffer questionnaire ( $>60 \%$ of patients in all groups). About $65 \%$ of patients were not dependent on assistance for activities of daily living (ADLs). The median Charlson comorbidity index score was 7 (high comorbidity). Most patients (90\%) had a life expectancy $\geq 6$ months according to the investigator's estimation.

Compared with autonomous patients, non-autonomous patients were older (84 [80-88] vs. 78 [72-83] years; $p<0.001)$, predominantly female $(62.3 \%$ vs. $43.7 \%$; $p<0.001)$, and with higher risk of stroke and bleeding according to $\mathrm{CHA}_{2} \mathrm{DS}_{2}$-VASc (5.6 \pm 1.5 vs. $4.4 \pm 1.5$; $p<0.001)$ and HAS-BLED $(3.4 \pm 1.1 \quad$ vs. $2.8 \pm 1.1$; $p<0.001)$ scores. Similarly, patients with cognitive impairment had a more advanced age (83 [79-88] vs. 79.0 [73-84] years; $p<0.001)$, were mostly women $(61.2 \%$ vs. $45.1 \% ; p<0.001)$, and had higher $\mathrm{CHA}_{2} \mathrm{DS}_{2}$-VASc $(5.2 \pm 1.6$ vs. $4.6 \pm 1.6 ; \quad p<0.001)$ and HAS-BLED $(3.1 \pm 1.2$ vs. $2.9 \pm 1.1 ; p<0.001)$ scores compared with patients without cognitive impairment. Additionally, the median age of patients with $<4$ comorbidities was 64 (5467) years while it was $81(75-86)$ years in patients with $\geq 4$ comorbidities $(p<0.001)$ in whom $\mathrm{CHA}_{2} \mathrm{DS}_{2}$-VASc and HAS-BLED scores were higher (vs. $<4$ comorbidities) $\left(\mathrm{CHA}_{2} \mathrm{DS}_{2}\right.$-VASc: $4.9 \pm 1.5$ vs. $1.9 \pm 1.0 ; p<0.001$; HASBLED: $3.1 \pm 1.1$ vs. $1.2 \pm 1.0 ; p<0.001)$. Patients with a life expectancy $<6$ months (vs. $\geq 6$ months) were older (86 [81-91] vs. 80 [74-85] years; $p<0.001)$ and with higher $\mathrm{CHA}_{2} \mathrm{DS}_{2}$-VASc $(5.3 \pm 1.6$ vs. $4.7 \pm 1.6 ; p<0.001)$ and HAS-BLED $(3.5 \pm 1.2$ vs. $2.9 \pm 1.1 ; p<0.001)$ scores.

The differences in sociodemographic and functional characteristics, morbidity and life expectancy between the patients undergoing different antithrombotic treatment strategies are shown in Table 1 . There were statistically significant differences in terms of age and educational level between the different treatment groups. 


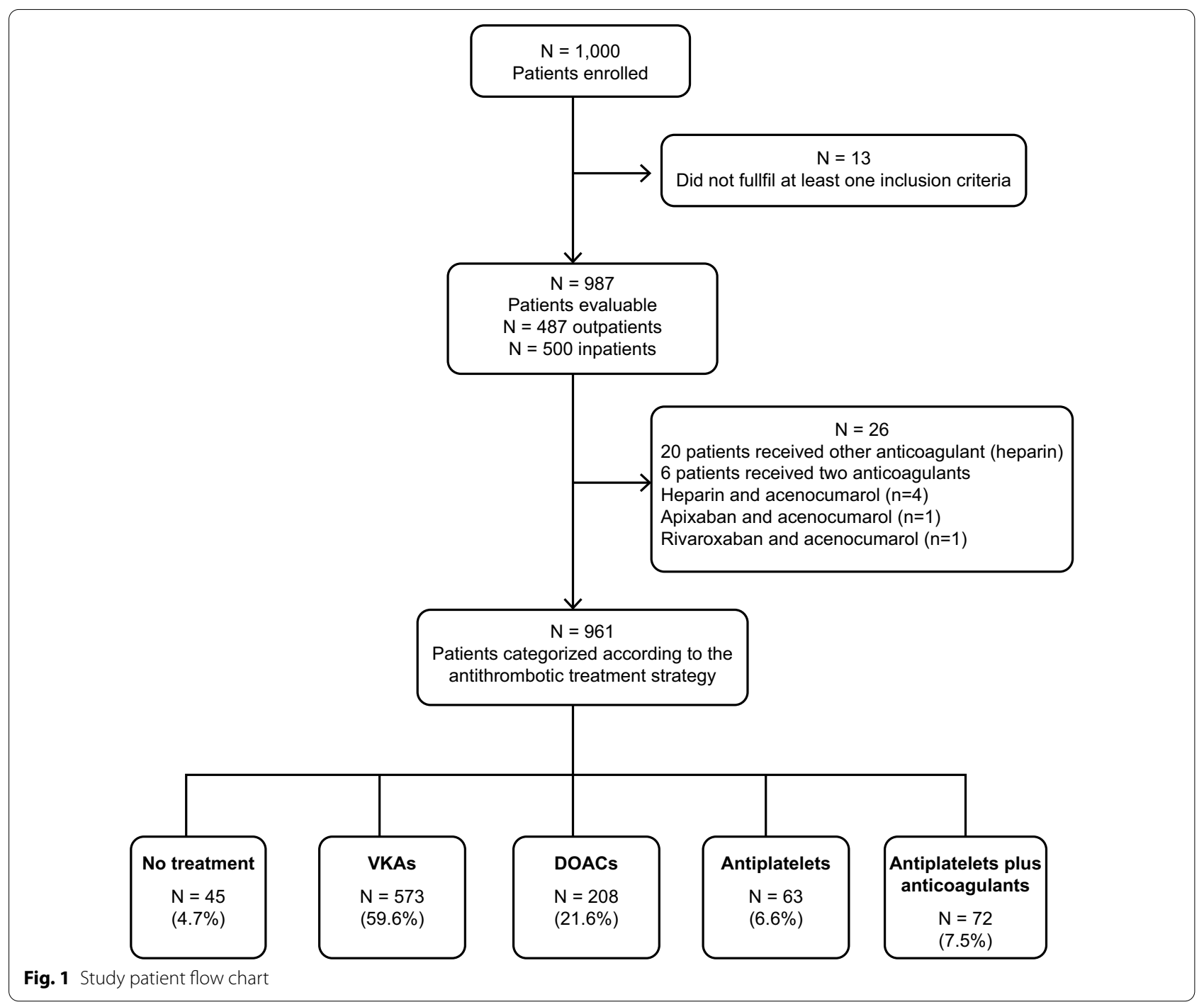

Significant differences in functional characteristics (institutionalization, dependence in ADLs, and functional disability measured by the Barthel index) were also observed between the different treatment groups except in terms of cognitive impairment. In addition, there were statistically significant differences in estimated prognostic characteristics, including comorbidity (Charlson comorbidity index score), 1-year mortality risk (PROFUND index) and life expectancy (investigator's clinical judgment) among the patients treated with the different antithrombotic treatment strategies.

\section{Clinical characteristics}

Clinical characteristics according to the antithrombotic treatment strategy are shown in Table 2. Most patients were diagnosed with permanent $\operatorname{NVAF}(70 \%)$, with a median time since diagnosis of over four years. The most common comorbidities were hypertension (90\%), congestive heart failure (CHF) (54\%), renal disease (43\%), and diabetes mellitus (40\%). A history of bleeding was present in less than $15 \%$ of patients.

The vast majority of patients had high thromboembolic risk according to the $\mathrm{CHA}_{2} \mathrm{DS}_{2}$-VASc score $(\geq 2)$, with more than $45 \%$ of patients with a score $\geq 5$ in all treatment groups. Most patients $(>60 \%)$ had a HAS-BLED score $\geq 3$.

The differences in clinical characteristics between the patients undergoing different antithrombotic treatment strategies are shown in Table 2. There were statistically significant differences in the type of NVAF and the median time since diagnosis among treatment groups. Cardiovascular history also differed among the patients treated with each antithrombotic therapy except for CHF. No significant differences were found 
Table 1 Patient's sociodemographic and functional characteristics, morbidity and life expectancy, according to antithrombotic treatment strategy

\begin{tabular}{|c|c|c|c|c|c|c|c|}
\hline Characteristics & No treatment & VKAs & DOACs & Antiplatelets & $\begin{array}{l}\text { Antiplatelets }+ \\
\text { anticoagulants }\end{array}$ & Overall & $p$ value \\
\hline No. (\%) & $45(4.7)$ & $573(59.6)$ & $208(21.6)$ & $63(6.6)$ & $72(7.5)$ & $961(100.0)$ & - \\
\hline Age, median $(\mathrm{IQR})$, years ${ }^{\mathrm{a}}$ & $83.0(74.5-88.0)$ & $81.0(75.0-86.0)$ & $80.0(74.0-85.0)$ & $83.0(76.0-88.0)$ & $78.0(70.0-82.8)$ & $81.0(75.0-86.0)$ & 0.001 \\
\hline$\geq 85$ years, $\mathrm{n}(\%)$ & $19(42.2)$ & $175(30.5)$ & $56(26.9)$ & $27(42.9)$ & $11(15.3)$ & $288(30.0)$ & 0.002 \\
\hline Gender, male, n (\%) ${ }^{b}$ & $24(53.3)$ & $285(49.7)$ & $91(43.8)$ & $30(47.6)$ & $46(63.9)$ & $476(49.5)$ & 0.059 \\
\hline$B M I$, median (IQR), $\mathrm{Kg} / \mathrm{m}^{2 \mathrm{a}}$ & $24.6(22.7-27.7)$ & $28.0(24.9-31.7)$ & $27.8(24.2-31.4)$ & $26.4(23.5-30.7)$ & $29.2(25.3-33.6)$ & $27.7(24.8-31.6)$ & 0.001 \\
\hline Educational level, $\mathrm{n}(\%)^{\mathrm{b}}$ & & & & & & & 0.047 \\
\hline $\begin{array}{l}\text { Did not complete com- } \\
\text { pulsory education }\end{array}$ & $10(23.8)$ & $114(20.9)$ & $36(17.9)$ & $10(16.9)$ & $14(20.0)$ & $184(20.0)$ & \\
\hline Primary education & $22(52.4)$ & $348(63.7)$ & $113(56.2)$ & $33(55.9)$ & $45(64.3)$ & $561(61.1)$ & \\
\hline Secondary education & $4(9.5)$ & $61(11.2)$ & $33(16.4)$ & $10(16.9)$ & $8(11.4)$ & $116(12.6)$ & \\
\hline University or higher & $6(14.3)$ & $23(4.2)$ & $19(9.5)$ & $6(10.2)$ & $3(4.3)$ & $57(6.2)$ & \\
\hline Institutionalized, $\mathrm{n}(\%)^{\mathrm{c}}$ & $4(8.9)$ & $41(7.2)$ & $2(1.0)$ & $9(14.3)$ & $2(2.8)$ & $58(6.1)$ & $<0.001$ \\
\hline $\begin{array}{l}\text { Dependence in } A D L s, n \\
(\%)^{b}\end{array}$ & $18(40.9)$ & $187(32.7)$ & $63(30.3)$ & $34(54.0)$ & $25(34.7)$ & $327(34.1)$ & 0.008 \\
\hline $\begin{array}{l}\text { Barthel index score }<60 \\
\text { (severe/total depend- } \\
\text { ence), } \mathrm{n}(\%)^{\mathrm{b}}\end{array}$ & $15(33.3)$ & $84(14.7)$ & $33(15.9)$ & $23(36.5)$ & $7(9.7)$ & $162(16.9)$ & $<0.001$ \\
\hline $\begin{array}{l}\text { Charlson index, median } \\
(I Q R)^{c}\end{array}$ & $7.0(5.5-9.0)$ & $7.04(6.0-9.0)$ & $7.0(5.0-8.0)$ & $8.0(6.0-9.0)$ & $8.0(6.0-10.0)$ & $7.04(6.0-9.0)$ & 0.009 \\
\hline $\begin{array}{l}\text { Cognitive impairment } \\
\text { (SPMSQ score), } n(\%) b\end{array}$ & $13(28.9)$ & $172(30.2)$ & $65(31.3)$ & $23(36.5)$ & $18(25.0)$ & $291(30.4)$ & 0.692 \\
\hline Score $>7$ (severe) & $3(6.7)$ & $86(15.0)$ & $37(17.8)$ & $12(19.0)$ & $7(9.7)$ & $145(15.1)$ & 0.194 \\
\hline $\begin{array}{l}\text { PROFUND index score, } \\
\text { median }(I Q R)^{a}\end{array}$ & $6.0(1.0-10.5)$ & $3.0(0.0-6.0)$ & $3.0(0.0-5.8)$ & $5.0(0.0-10.0)$ & $2.0(0.0-5.0)$ & $3.0(0.0-6.0)$ & $<0.001$ \\
\hline $\begin{array}{l}\text { 1-year mortality risk, } \mathrm{n} \\
(\%)^{\mathrm{b}}\end{array}$ & & & & & & & $<0.001$ \\
\hline Low (12.1-14.6\%) & $14(31.1)$ & $258(45.0)$ & $99(47.6)$ & $17(27.0)$ & $37(51.4)$ & $425(44.2)$ & \\
\hline $\begin{array}{l}\text { Low-intermediate } \\
\quad(21.5-31.5 \%)\end{array}$ & $10(22.2)$ & $191(33.3)$ & $72(34.6)$ & $17(27.0)$ & $24(33.3)$ & $314(32.7)$ & \\
\hline $\begin{array}{l}\text { Intermediate-high } \\
(45.0-50.0 \%)\end{array}$ & $10(22.2)$ & $72(12.6)$ & $19(9.1)$ & $17(27.0)$ & $9(12.5)$ & $127(13.2)$ & \\
\hline High (61.3-68.0\%) & $11(24.4)$ & $52(9.1)$ & $18(8.7)$ & $12(19.0)$ & $2(2.8)$ & $95(9.9)$ & \\
\hline Life expectancy, n (\%) ${ }^{\mathrm{b}}$ & & & & & & & $<0.001$ \\
\hline$\geq 6$ months & $34(75.6)$ & $522(91.1)$ & $196(94.2)$ & $53(84.1)$ & $68(94.4)$ & $873(90.8)$ & \\
\hline$<6$ months & $11(24.4)$ & $51(8.9)$ & $12(5.8)$ & $10(15.9)$ & $4(5.6)$ & $88(9.2)$ & \\
\hline
\end{tabular}

$A D L$ activities of daily living, $B M I$ body mass index, DOAC direct-acting oral anticoagulant, IQR interquartile range, SD standard deviation, SPMSQ Pfeiffer Short Portable Mental Status Questionnaire, VKA vitamin K antagonist

For normally distributed data, mean and standard deviation are used, and for data not normally distributed, median with interquartile range are used. ${ }^{a}$ Nonparametric Kruskal-Wallis test, ${ }^{\mathrm{b}} \mathrm{Chi}$-square test, ${ }^{\mathrm{C}}$ Fisher's exact test

in the percentage of patients with high thromboembolic risk $\left(\mathrm{CHA}_{2} \mathrm{DS}_{2}\right.$-VASc $\left.\geq 2\right)$ who were treated with each antithrombotic therapy. However, the percentage of patients with high hemorrhagic risk (HAS-BLED) differed significantly by treatment strategy $(p<0.001)$.

Factors associated with antithrombotic treatment patterns The results of the multivariate analysis performed to identify the independent factors associated with the use of OAC versus antiplatelet therapy and of DOACs versus VKAs are summarized in Table 3.

\section{Factors associated with the use of OAC versus antiplatelet therapy}

The presence of CHF (OR, 2.084) and permanent NVAF (OR, 4.122) was associated with preferential use of OAC over antiplatelets, while intermediate- to high-mortality risk according to the PROFUND index (vs. low mortality risk) (OR, $0.455 ; 0.144$, and 0.133 respectively) was associated with a higher likelihood of using antiplatelet therapy alone instead of OAC. 
Table 2 Clinical characteristics of the overall population and according to antithrombotic treatment strategy

\begin{tabular}{|c|c|c|c|c|c|c|c|}
\hline Characteristics & No treatment & VKAs & DOACs & Antiplatelets & $\begin{array}{l}\text { Antiplatelets }+ \\
\text { anticoagulants }\end{array}$ & Overall & $p$ value \\
\hline No. (\%) & $45(4.7)$ & $573(59.6)$ & $208(21.6)$ & $63(6.6)$ & $72(7.5)$ & $961(100.0)$ & -- \\
\hline Inpatient/Outpatient, n (\%) & $21(46.7) / 24(53.3)$ & $\begin{array}{l}301(52.5) / 272 \\
(47.5)\end{array}$ & $\begin{array}{c}70(33.7) / 138 \\
(66.3)\end{array}$ & $46(73.0) / 17(27.0)$ & $43(59.7) / 29(40.3)$ & $\begin{array}{l}481(50.1) / 480 \\
(49.9)\end{array}$ & -- \\
\hline Type of NVAF, n (\%) ${ }^{b}$ & & & & & & & $<0.001$ \\
\hline Paroxysmal & $21(46.7)$ & $90(15.7)$ & $52(25.0)$ & $26(41.3)$ & $14(19.4)$ & $203(21.1)$ & \\
\hline Persistent & $6(13.3)$ & $47(8.2)$ & $19(9.1)$ & $6(9.5)$ & $7(9.7)$ & $85(8.8)$ & \\
\hline Permanent & $18(40.0)$ & $436(76.1)$ & $137(65.9)$ & $31(49.2)$ & $51(70.8)$ & $673(70.0)$ & \\
\hline $\begin{array}{l}\text { Time since diagnosis, } \\
\text { median (IQR), years a }\end{array}$ & $2.5(0.1-7.2)$ & $4.7(2.3-9.0)$ & $3.0(1.3-8.0)$ & $5.0(1.0-8.2)$ & $3.9(1.4-8.3)$ & $4.2(1.7-8.6)$ & $<0.001$ \\
\hline \multicolumn{8}{|l|}{ Comorbidities, n (\%) b } \\
\hline Active neoplasia & $11(24.4)$ & $76(13.3)$ & $24(11.5)$ & $12(19.0)$ & $10(13.9)$ & $133(13.8)$ & 0.149 \\
\hline COPD & $9(20.0)$ & $164(28.6)$ & $53(25.5)$ & $15(23.8)$ & $21(29.2)$ & $262(27.3)$ & 0.631 \\
\hline Renal disease/CKD & $17(37.8)$ & $180(31.4)$ & $54(26.0)$ & $23(36.5)$ & $24(33.3)$ & $298(31.0)$ & 0.336 \\
\hline \multicolumn{8}{|l|}{$\begin{array}{l}\text { Cardiovascular history, } \\
\text { n (\%) }\end{array}$} \\
\hline Congestive heart failure & $21(46.7)$ & $323(56.4)$ & $106(51.0)$ & $28(44.4)$ & $44(61.1)$ & $522(54.3)$ & 0.147 \\
\hline Ischaemic disease ${ }^{d}$ & $1(2.2)$ & $101(17.6)$ & $28(13.5)$ & $12(19.0)$ & $37(51.4)$ & $179(18.6)$ & $<0.001$ \\
\hline Peripheral artery disease & $1(2.2)$ & $43(7.5)$ & $17(8.2)$ & $9(14.3)$ & $18(25.0)$ & $88(9.2)$ & $<0.001$ \\
\hline Stroke/TIA & $8(17.8)$ & 95 (16.6) & $47(22.6)$ & $17(27.0)$ & $22(30.6)$ & $189(19.7)$ & 0.016 \\
\hline $\begin{array}{l}\text { Arterial thromboembo- } \\
\text { lism/venous thrombo- } \\
\text { embolic disease, n (\%) }\end{array}$ & $2(4.4)$ & $29(5.1)$ & $9(4.3)$ & $2(3.2)$ & $2(2.8)$ & $44(4.6)$ & 0.885 \\
\hline Hypertension, n (\%) & $35(77.8)$ & $519(90.6)$ & $191(91.8)$ & $54(85.7)$ & $65(90.3)$ & $864(89.9)$ & 0.047 \\
\hline Diabetes mellitus, n (\%) & $10(22.2)$ & $237(41.4)$ & $72(34.6)$ & $31(49.2)$ & $36(50.0)$ & $386(40.2)$ & 0.007 \\
\hline $\begin{array}{l}\text { Abnormal hepatic func- } \\
\text { tion }^{e}, \mathrm{n}(\%)\end{array}$ & $2(4.4)$ & $37(6.5)$ & $14(6.7)$ & $6(9.5)$ & $2(2.8)$ & $61(6.3)$ & 0.590 \\
\hline $\begin{array}{l}\text { Abnormal renal function } \\
\mathrm{f}, \mathrm{n}(\%)\end{array}$ & $20(44.4)$ & $249(43.5)$ & $82(39.4)$ & $31(49.2)$ & $32(44.4)$ & $414(43.1)$ & 0.695 \\
\hline Prior bleeding, n (\%) ${ }^{b}$ & $8(17.8)$ & $71(12.4)$ & $33(15.9)$ & $9(14.3)$ & $10(13.9)$ & $131(13.6)$ & 0.678 \\
\hline $\begin{array}{c}\mathrm{CHA}_{2} \mathrm{DS}_{2}-\text { VASC score, } \\
\text { median (IQR) }^{\text {a }}\end{array}$ & $4.0(4.0-5.5)$ & $5.0(4.0-6.0)$ & $5.0(4.0-6.0)$ & $5.0(4.0-6.0)$ & $5.0(4.0-6.8)$ & $5.0(4.0-6.0)$ & 0.097 \\
\hline Risk categories, $\mathrm{n}(\%)^{\mathrm{c}}$ & & & & & & & $<0.001$ \\
\hline 0 & $4(8.9)$ & $0(0.0)$ & $0(0.0)$ & $1(1.6)$ & $0(0.0)$ & $5(0.5)$ & \\
\hline 1 & $0(0.0)$ & $6(1.0)$ & $1(0.5)$ & $0(0.0)$ & $1(1.4)$ & $8(0.8)$ & \\
\hline$\geq 2$ & $41(91.1)$ & $567(99.0)$ & $207(99.5)$ & $62(98.4)$ & $71(98.6)$ & 948 (98.6) & \\
\hline Score $\geq 5, \mathrm{n}(\%)$ & $19(46.4)$ & $330(58.2)$ & $112(54.6)$ & $39(62.9)$ & $47(66.0)$ & $547(57.6)$ & \\
\hline $\begin{array}{l}\text { HAS-BLED score, median } \\
(\mathrm{IQR})^{\mathrm{a}}\end{array}$ & $3.0(2.0-3.0)$ & $3.0(2.0-4.0)$ & $3.0(2.0-4.0)$ & $4.0(3.0-4.0)$ & $4.0(3.0-5.0)$ & $3.0(2.0-4.0)$ & $<0.001$ \\
\hline Risk categories, n (\%) ${ }^{b}$ & & & & & & & $<0.001$ \\
\hline$<3$ & $22(48.9)$ & $228(39.8)$ & $75(36.1)$ & $7(11.1)$ & $5(6.9)$ & $337(35.1)$ & \\
\hline$\geq 3$ & $23(51.1)$ & $345(60.2)$ & $133(63.9)$ & $56(88.9)$ & $67(93.1)$ & $624(64.9)$ & \\
\hline
\end{tabular}

NVAF non-valvular atrial fibrillation, COPD chronic obstructive pulmonary disease, $C K D$ chronic kidney disease, $D O A C$ direct-acting oral anticoagulant, $I Q R$ interquartile range, $S D$ standard deviation, TIA transient ischemic attack, VKA vitamin $\mathrm{K}$ antagonist

For normally distributed data, mean and standard deviation are used, and for data not normally distributed, median with interquartile range are used. ${ }^{\mathrm{N}} \mathrm{Non}-$ parametric Kruskal-Wallis test, ${ }^{\mathrm{b}} \mathrm{Chi}$-square test, ${ }^{\mathrm{C}}$ Fisher's exact test. ${ }^{\mathrm{d}}$ Includes myocardial infarction and stable coronary artery disease, ${ }^{\mathrm{e}} \mathrm{chronic}$ hepatic disease (e.g. cirrhosis) or biochemical data indicative of significant hepatic damage (e.g. bilirubin $>2 \times$ the upper normal limit, associated with AST/ALT $>3 \times$ the upper normal limit, etc.), ${ }^{f}$ chronic dialysis, renal transplant or serum creatinine $\geq 200 \mu \mathrm{mol} / \mathrm{I}$ ) (yes/no) and renal disease staging based on the glomerular filtration rate (GFR) according to the Kidney Disease Improving Global Outcomes (KDIGO) guidelines G3a, 45-59 mL/min/1,73 m²; G3b, 30-44 mL/min/1.73 m²; G4, 15-29 mL/min/1.73 $\mathrm{m}^{2} ;$ or $\mathrm{G} 5,<15 \mathrm{~mL} / \mathrm{min} / 1.73 \mathrm{~m}^{2}$ 


\section{Factors associated with the use of DOACs versus VKAs}

Factors significantly associated with the use of VKAs over DOACs were longer time since diagnosis (OR, 1.045) and institutionalization (OR, 7.744). However, female gender (vs. male), secondary or university or higher studies, and having suffered a stroke/transient ischemic attack (OR, 0.591 ) were factors associated with preferential use of DOACs.

\section{Discussion}

The present study assessed the demographic, functional, and clinical characteristics associated with antithrombotic treatment patterns in a large real-life population of patients with NVAF. The median age of patients was about 80 years, and most patients had permanent NVAF, with a median disease duration of over four years. As expected, this elderly population had a high comorbidity burden, particularly cardiovascular risk factors and disease, a very high thromboembolic risk and a moderate to high risk of bleeding. Most patients were autonomous and had no cognitive impairment. Patients with worse functional status and worse prognosis in terms of survival were those with more advanced age and with a higher risk of stroke and bleeding.

Despite being a population comprised of elderly patients with a high comorbidity burden, we found that the vast majority of patients (95\%) were receiving antithrombotic treatment due to their high thromboembolic risk. Most patients received VKA treatment (60\%) while DOACs were given in less than one-quarter of patients. Of note, antiplatelet therapy alone was prescribed in less than $7 \%$ of patients with NVAF in routine clinical practice.

Older age is a common reason given for not prescribing anticoagulation $[20,28]$. Thus, the high use of OAC shown in this real-world analysis (88\%) was especially interesting, since $75 \%$ of patients were older than 75 years and $30 \%$ of patients were aged $\geq 85$ years. This study has therefore highlighted that age alone was not considered as a contraindication for anticoagulation. The underuse of OAC in elderly patients is mainly due to overestimation of the risk of bleeding in these patients [29]. However, the benefit of stroke prevention outweighs the potential increased risk of bleeding in these patients $[30,31]$, in whom a higher net clinical benefit has been demonstrated compared to the younger population due to their higher thromboembolic risk [32]. We found a substantial increase in the use of OAC in elderly patients compared to prior studies conducted in octogenarian AF patients in Spain, where only half of the patients received anticoagulation [33]. This difference may suggest changes in physicians' perceptions of the benefits and risks of OAC for older NVAF patients based on the available evidence demonstrating its benefit in this population [20, 34].

Of note, the percentage of patients who received no antithrombotic treatment in our series (4.7\%) was similar to that previously reported in the European population of the GLORIA-AF registry (4.1\%) [35]. However, compared to other European studies, our analysis showed a significantly lower proportion of untreated patients [36, 37]. A higher rate of untreated patients has also been reported among elderly patients in the internal medicine setting in Spain (13.8\%) [38].

Although a history of prior bleeding has traditionally been associated with anticoagulation under-prescription in elderly patients [39], bleeding history was not identified as a factor contributing to anticoagulation underuse in our study. Indeed, a high HAS-BLED score should not be a reason for non-prescription of anticoagulation but rather a tool to identify and control modifiable bleeding risk factors to reduce the risk of bleeding [40, 41].

Antiplatelet therapy has traditionally been used instead of anticoagulation to prevent the risk of bleeding despite the demonstrated greater efficacy of anticoagulant treatment over antiplatelet agents without increasing major bleeding [42]. Nevertheless, we found that the use of antiplatelet therapy alone (7\%) was notably lower than that previously reported in primary care (20\%) [43]. Interestingly, antiplatelet therapy users were less frequent compared to prior national studies in elderly inpatients (about $18 \%)[38,44]$. Indeed, we found that compared to outpatients, the proportion of hospitalized patients receiving antiplatelet therapy was higher, probably because these patients are more likely to have frailty and more comorbidity compared to outpatients and thus may not be considered optimal candidates for anticoagulation [28].

Of note, institutionalized patients and those with total or partial dependence for daily activities, who were older and with higher thromboembolic and bleeding risk, were primarily treated with antiplatelets, which were also preferentially used in patients with functional disability and worse prognosis. These findings, therefore, suggest that there might be functional and prognostic factors driving the selection of antiplatelet therapy alone over OAC. Indeed, the univariate analysis showed that institutionalization, dependence for daily activities, 1-year mortality risk assessed by the PROFUND index, and life expectancy (physician's clinical judgment) were factors significantly associated with preferential use of antiplatelet therapy over OAC. However, among these factors, only 1 -year mortality risk was retained in the multivariate model, which showed that poor prognosis (intermediate or high risk) was a factor contributing to OAC non-prescription in favor of antiplatelet therapy alone. 
Table 3 Factors associated with treatment strategy for NVAF by multivariate analysis

\begin{tabular}{|c|c|c|}
\hline Endpoint $^{\mathrm{a}}$ & OR $(95 \% \mathrm{Cl})$ & $p$ value \\
\hline \multicolumn{3}{|l|}{ Anticoagulants versus antiplatelet therapy ${ }^{b}$} \\
\hline PROFUND Index (1-year mortality risk) (Referral category: low) & & $<0.0001$ \\
\hline Low-intermediate & $0.455(0.221-0.938)$ & 0.033 \\
\hline Intermediate-high & $0.144(0.067-0.312)$ & $<0.0001$ \\
\hline High & $0.133(0.056-0.316)$ & $<0.0001$ \\
\hline Type of NVAF (Referral category: paroxysmal) & & $<0.0001$ \\
\hline Persistent & $2.077(0.796-5.422)$ & 0.135 \\
\hline Permanent & $4.122(2.281-7.450)$ & $<0.0001$ \\
\hline Congestive heart failure (yes vs. no) & $2.084(1.173-3.703)$ & 0.012 \\
\hline \multicolumn{3}{|l|}{ VKAs versus $D O A C s^{c}$} \\
\hline Gender (male vs. female) & $0.677(0.478-0.959)$ & 0.028 \\
\hline $\begin{array}{l}\text { Educational level (Referral category: did not complete compulsory educa- } \\
\text { tion) }\end{array}$ & & 0.004 \\
\hline Primary education & $0.959(0.617-1.491)$ & 0.853 \\
\hline Secondary education & $0.534(0.297-0.961)$ & 0.036 \\
\hline University or higher & $0.337(0.159-0.715)$ & 0.023 \\
\hline Institutionalization (yes vs. no) & $7.744(1.816-33.027)$ & 0.006 \\
\hline Time since diagnosis of NVAF & $1.045(1.011-1.080)$ & 0.009 \\
\hline Prior stroke/TIA (yes vs. no) & $0.591(0.386-0.903)$ & 0.015 \\
\hline
\end{tabular}

$\mathrm{Cl}$ : confidence interval, DOAC: direct-acting oral anticoagulant, NVAF non-valvular atrial fibrillation, OR: odds ratio, TIA: transient ischemic attack, VKA: vitamin K antagonist

${ }^{\text {a }}$ The covariates included in the univariate models were as follows: age, gender, educational level, institutionalization, dependence in activities of daily living (ADLs), PROFUND index, Charlson comorbidity index, cognitive impairment (SPMSQ score), life expectancy (physician's criteria), type of NAVF, time since diagnosis of NVAF, active neoplasia, dementia, diabetes mellitus, hypertension, congestive heart failure (CHF), ischaemic disease (myocardial infarction, and/or stable coronary arterial disease), peripheral artery disease (PAD), cerebrovascular disease (prior stroke/transient ischemic attack [TIA]), venous thromboembolic disease, prior bleeding, predisposition to bleeding, abnormal hepatic function, abnormal renal function, and thromboembolic risk (CHA $\mathrm{CS}_{2}$-VASc score)

${ }^{\mathrm{b}}$ The variables included in the multivariate analysis were institutionalization $(p=0.005)$, dependence in ADLs $(p=0.001), 1$-year risk mortality risk (PROFUND index) $(p<0.0001)$, Charlson comorbidity index $(p=0.012)$, life expectancy $(p=0.031)$, type of NVAF $(p<0.001)$, and dementia ( $p=0.007)$. Age $(p=0.098)$, diabetes mellitus $(p$ $=0.174)$, arterial hypertension $(p=0.183), \operatorname{CHF}(p=0.092), \operatorname{PAD}(p=0.183)$, and prior stroke/TIA $(p=0.138)$ were also considered in the multivariate model ( $p<0.2)$

${ }^{c}$ The variables included in the multivariate analysis were educational level ( $\left.p=0.008\right)$, institutionalization $(p=0.005)$, Charlson comorbidity index ( $\left.p=0.029\right)$, type of $\operatorname{NVAF}(p=0.009)$, and time since diagnosis of $\operatorname{NVAF}(p<0.008)$. Gender $(p=0.139)$, life expectancy $(p=0.159)$, diabetes mellitus $(p=0.089)$, CHF $(p=0.180)$, ischemic disease ( $p=0.167)$, and prior stroke/TIA ( $p=0.055)$ were also considered in the multivariate model $(p<0.2)$. Prior bleeding ( $p=0.208)$ and abnormal renal function (0.314) were also included as relevant determinants of anticoagulant treatment

This real-world assessment has also highlighted that the type of NVAF appears to be a factor that has played an essential role in the underuse of OAC in NVAF. In this regard, we found that patients with paroxysmal NVAF were more likely to receive antiplatelet therapy alone instead of OAC compared to patients with permanent NVAF in line with prior reports $[1,35,45]$. The underuse of OAC in favor of antiplatelet therapy in patients with paroxysmal NVAF could be due to the perception of a lower thromboembolic risk associated with this type of NVAF [46]. However, contrary findings regarding its impact on thromboembolic risk have been reported [47, 48]. Nevertheless, according to current guidelines [16], the decision concerning antithrombotic therapy should be based on the patient's risk of stroke and bleeding, regardless of the type of NVAF.

Regarding the type of OAC, we found that a significant proportion of patients still received VKAs over DOACs despite guideline recommendations [16]. The use of
DOACs among patients receiving OAC (24.4\%) was similar to that reported in Spanish studies conducted at the regional level during 2015 (24\%) and 2011-2014 (25\%) [49] and the nationwide FANTASIIA registry (22\%) [50]. Thus, a substantial proportion of Spanish NVAF patients who could benefit from DOACs did not receive them, as recognized by experts [51]. In addition, the preference for VKAs over DOACs may be due to the lack of available targeted DOAC reversal agents for patients with bleeding at the time of the study. Moreover, the prescription of DOACs can be challenging in Spain due to the restrictions for their use stated in the national Therapeutic Positioning Report (TPR) [52] and the different administrative requirements of the Spanish Autonomous Communities. This study also found that the use of DOACs in Spain is still far behind other European countries, where an overall rate of DOAC prescription of approximately $50 \%$ [35] has been reported. However, geographical 
differences have been found in prescription patterns [36, 53, 54].

We found that neither the functional characteristics nor the prognosis (PROFUND index) or morbidity were associated with the use of DOACs. Nevertheless, preferential use of VKAs over DOACs was found among institutionalized patients, probably due to a more controlled environment which may enhance VKA treatment adherence and might avoid unacceptable risks derived from poor anticoagulation control. There appear to be sociodemographic factors driving DOAC selection, such as gender and educational level. Thus, educational level was identified as an independent factor associated with the use of DOACs, with a preference of these agents over VKAs in more educated patients, probably also with a higher income, in line with prior reports [55]. This may be explained by better access of patients with a high educational level to the available information on new oral anticoagulants, which may influence treatment decision for stroke prevention. In addition, patients with longer disease duration were also more likely to receive VKA therapy over DOACs probably because prescription of DOACs may have only increased over the past few years due to current guidelines recommendation [16]. A prior history of stroke was also associated with a higher likelihood of receiving DOACs according to the European recommendations [16].

DOAC prescription has been traditionally limited by renal function, especially in elderly patients whose renal function is often unstable and affected by concomitant comorbidities and hospitalizations [56, 57]. However, abnormal renal function was not identified as a factor contributing to DOAC non-prescription, in contrast to other reports in the primary care setting [49]. Indeed, renal impairment should not be a limitation to DOAC prescription and reduced dose regimens of DOACs are approved for use in moderate and severe chronic kidney disease.

The main limitations of this study are due to the research design. This was a cross-sectional study which included a mixed incident and prevalent NVAF population; new starters and switchers from antithrombotic therapy, who were selected from a large sample of hospitals in Spain. However, it is noteworthy that this study did not aim to focus on treatment patterns, such as switching or discontinuation. In addition, we must take into account the obvious limitations of a retrospective chart review that uses patients' data already recorded in the medical charts for reasons other than research, including incomplete or unrecorded information. A further limitation that should be acknowledged is the unequal number of patients in each group defined by the therapeutic strategy used for NVAF management. However, we should note that these groups were created according to clinical practice, given that patients could be receiving any treatment for NVAF when they were included in the study. Indeed, this study did not aim to assess the differences between these groups, and the comparisons made between them are exploratory and descriptive. Despite these limitations, this study provides valuable real-world data on the profile and treatment patterns of NVAF patients and grounds for discussion on whether antithrombotic treatment strategies are in line with guideline recommendations. Thus, the findings obtained in this analysis may be used to identify critical issues that should be improved in the management of NVAF patients, which might optimize patient care and outcomes. The strengths of this study include a highly representative population of non-selected elderly patients with NVAF in clinical practice, including inpatients and outpatients, attended in the internal medicine departments of more than 90 hospitals distributed homogeneously throughout the country. To our knowledge, this is the first and the most extensive study to assess the real-world characteristics of NVAF patients according to antithrombotic treatment after approval of DOACs in the internal medicine setting in Spain.

\section{Conclusion}

This study showed that the vast majority of elderly patients with NVAF, with high comorbidity burden and high thromboembolic risk, received OAC in the realworld setting, with VKAs as the most frequently prescribed treatment, while DOACs remained underused. Longer duration of $\mathrm{AF}$ and institutionalization were identified as determinants of VKA use over DOACs. Antiplatelet therapy was still offered to a proportion of patients. A poor prognosis according to the PROFUND index was identified as a factor preventing the use of OAC.

\section{Abbreviations}

ADL: Activities of daily living; AF: Atrial fibrillation; CHF: Congestive heart failure; Cl: Confidence interval; DOAC: Direct oral anticoagulants; NVAF: Non-valvular atrial fibrillation; OAC: Oral anticoagulation; OR: Odds ratio; VKA: Vitamin Kantagonist.

\section{Acknowledgements}

The authors would like to acknowledge the investigators of the PERFILAR study for its contribution to the study. We also thank Cristina Vidal and Antonio Torres from Dynamic Science (Spain) for their medical writing support, funded by Alliance Bristol-Myers Squibb/Pfizer, Spain. The authors would also like to thank Alliance Bristol-Myers Squibb/Pfizer for sponsoring/supporting the study.

Investigators of the PERFILAR study group (collaborators): Fernando Javier Sánchez Lora, Hospital Clínico Universitario Virgen de la Victoria, Málaga (Spain); Francisco Ibañez Bermúdez, Hospital Comarcal Infanta Margarita, Córdoba (Spain); Ana María Jurado Porcel, Complejo Hospitalario Regional Reina Sofía, Córdoba (Spain); Fernando Salgado Ordoñez, Complejo Hospitalario Regional de Málaga (Hospital Carlos Haya), Málaga (Spain); Francisco Rivera 
Civico, Complejo Hospitalario de Poniente, El Ejido, Almería (Spain); Luis Felipe Díez García, Hospital Torrecárdenas, Almeria (Spain); Fernando Jaén Águila, Hospital Universitario Virgen de las Nieves, Granada (Spain); Manuel Geraldía Lama, Hospital Virgen de las Montañas, Cádiz (Spain); Enrique Peral GutiérrezCeballos, Complejo Hospitalario Virgen Macarena, Sevilla (Spain); Antonia Domínguez, Hospital Quironsalud Sagrado Corazón, Sevilla (Spain); Francisco Astudillo Martín, Hospital Infanta Luisa, Sevilla (Spain); Eduardo Aguilar, Hospital de Alcañiz, Teruel (Spain); Juan Ferrando Vela, Hospital Royo Villanova, Zaragoza (Spain); Alfonso García Aranda, Hospital Universitario Miguel Servet, Zaragoza (Spain); Mercedes Sánchez Cembellín, Hospital San Agustín, Avilés, Asturias (Spain); Juan Francisco López Caleya, Hospital de Cabueñes, Gijón (Spain); Sixto Ruiz, Hospital Comarcal de Inca, Islas Baleares (Spain); Melchor Rodríguez Gaspar, Hospital Universitario de Canarias, Santa Cruz de Tenerife (Spain); Alicia Conde Martel, Hospital Universitario de Gran Canaria Doctor Negrín, Las Palmas de Gran Canaria, Las Palmas (Spain); José Luis Hernández Hernández, Hospital Universitario Marqués de Valdecilla, Santander (Spain): Ismael Abascal Carrera, Hospital Comarcal de Laredo, Laredo (Spain); Alfonso Pérez del Molino Castellanos, Hospital Sierrallana, Torrelavega, Cantabria (Spain); Esther Fernández Pérez, Complejo Asistencial Universitario de León, León (Spain); Juan Carlos Martínez Acitores, Complejo Asistencial Universitario de Burgos, Burgos (Spain); Luis Miguel Seisdedos Cortes, Complejo Asistencial de Zamora, Zamora (Spain); Laura Abad Manteca, Hospital Universitario Rio Hortega, Valladolid (Spain); Marco Budiño Sánchez, Complejo Asistencial de Ávila, Ávila (Spain); José Javier Moreno Palomares, Complejo Asistencial de Segovia, Segovia (Spain); Inmaculada Coca Prieto, Hospital Santa Bárbara, Ciudad Real (Spain); Ana Isabel Muñoz, Hospital Nuestra Señora del Prado, Talavera de la Reina, Toledo (Spain); Ángel Sánchez Castaño, Hospital Virgen de la Salud, Toledo (Spain); Lola Ruiz Ribó, Hospital Virgen de la Luz, Cuenca (Spain); Jordi Mascaró, Hospital de la Santa Creu i Sant Pau, Barcelona (Spain); César Morcillo Serra, Hospital Cima Sanitas, Barcelona (Spain); Teresa Auguet Quintillá, Hospital Universitari Joan XXIII, Tarragona (Spain); Francesz Marimón, Hospital Universitari de Sant Joan de Reus, Tarragona (Spain); Joaquín Fernández Solá, Hospital Clinic i Provincial, Barcelona (Spain); José María Suriñach, Hospital Universitari Vall d'Hebron, Barcelona (Spain); Pablo Marchena, Parc Sanitari Sant Joan de Deu, Barcelona (Spain); Antoni Riera-Mestre, Hospital Universitari de Bellvitge, Bellvitge Biomedical Research Institute (IDIBELL), L'Hospitalet de Llobregat, Barcelona (Spain); Pedro Armario, Hospital de Sant Joan Despí Moisés Broggi, Sant Joan Despí, Barcelona (Spain); Ferrán García Bragado, Hospital Universitari de Girona Dr. Josep Trueta, Girona (Spain); Fátima del Molino, Hospital Quirón Salud del Vallés, Sabadell, Barcelona (Spain); Oscar Sacristán, Hospital Santa María, Alcalá de Henares, Madrid (Spain); Pere Almagro, Hospital Mutua de Terrassa, Terrassa, Barcelona (Spain); Conxita Falgà, Hospital de Mataró, Mataró, Barcelona (Spain); Francisco José Muñoz Rodríguez, Hospital de Mollet, Mollet del Vallès, Barcelona (Spain); Riesco, Hospital del Vendrell, El Vendrell, Tarragona (Spain); Jorge Romero Requena, Hospital Perpetuo Socorro, Badajoz (Spain); José Carlos Arévalo Lorido, Complejo Hospitalario Llerena-Zafra, Llerena, Badajoz (Spain); Manuela Chiquero Palomo, Complejo Hospitalario de Cáceres, Cáceres (Spain); Ana Isabel de la Cruz, Hospital Virgen del Puerto, Plasencia, Cáceres (Spain), Agustín Pijerro, Hospital Infanta Cristina, Badajoz (Spain); Elena Fernández Bouza, Complexo Hospitalario Universitario Arquitecto Marcide-Novoa Santos, Ferrol, A Coruña (Spain); Juan José González Soler, Complexo Hospitalario Universitario de Ourense, Ourense (Spain); Manuel Jesús Núñez Fernández, Complexo Hospitalario Universitario de Pontevedra, Pontevedra (Spain); Javier De La Fuente Aguado, Hospital de Povisa, Vigo, Pontevedra (Spain); José Antonio Díaz Peromingo, Complejo Hospitalario Universitario de Santiago, Santiago de Compostela, A Coruña (Spain); Julián Fernández Martín, Complejo Hospitalario de Vigo, Vigo, Pontevedra (Spain); Rafael Daroca Pérez, Complejo Hospital San Pedro, Logroño, La Rioja (Spain); Dr. Jesús Castiella Herrero, Fundación Hospital Calahorra, Calahorra, La Rioja (Spain); M. Cruz Carreño, Hospital Puerta de Hierro, Madrid (Spain); Jorge Gómez Cerezo, Hospital Universitario Infanta Sofía, San Sebastián de los Reyes, Madrid (Spain); José Carlos Pontes Navarro, Hospital Clínico San Carlos, Madrid (Spain); José Felipe Varona Arche, Hospital Universitario HM Montepríncipe, Boadilla del Monte, Madrid (Spain); Daniel Ferreiro López, Hospital Universitario 12 de octubre, Madrid (Spain); Benjamín Muñoz Calvo, Hospital Universitario Príncipe de Asturias, Alcalá de Henares, Madrid (Spain); Jesús Manuel Casado Cerrada, Hospital Universitario de Getafe, Getafe, Madrid (Spain); María del Pilar Fidalgo Montero, Hospital Universitario del Henares, Coslada, Madrid (Spain); José Manuel Casas Rojo, Hospital Universitario Infanta Cristina, Parla, Madrid (Spain); Benjamín Herreros, Hospital Universitario Fundación Alcorcón, Alcorcón, Madrid (Spain); Guillermo Cuevas
Tascón, Hospital Universitario Infanta Leonor, Madrid (Spain); Antonio Muiño Miguez, Hospitalario General Universitario Gregorio Marañón, Madrid (Spain); Jorge Marrero Francés, Hospital de Fuenlabrada, Fuenlabrada, Madrid (Spain); Nicolas Ortega, Hospital Virgen de la Arrixaca, El Palmar, Murcia (Spain); Javier Trujillo, Hospital Santa Lucía, Cartagena, Murcia (Spain); Julio Sánchez Álvarez, Complejo Hospitalario de Navarra, Pamplona, Navarra (Spain); Jose Ignacio Catalán Ramos, Policlínica San José, Vitoria, Álava (Spain); Francisco Javier Fresco Benito, Hospital Santa Marina, Bilbao, Vizcaya (Spain); Ainhoa Anuzita Alegría, Clínica Virgen Blanca, Bilbao, Vizcaya (Spain); Carlos Teruel, Hospital Gral. Castellón, Castellón de la Plana, Castellón (Spain); Arturo Artero Mora, Hospital Doctor Peset, Valencia (Spain); Pedro Moral, Hospital La Fe, Valencia (Spain); José Miguel Seguí Ripoll, Hospital Universitario San Juan, Alicante (Spain); Fernando Bonilla Rovira, Hospital General de Elche. Elche, Alicante (Spain); Ana Maestre Peiro, Hospital del Vinalopó, Elche, Alicante (Spain).

\section{Authors' contributions}

JMM, CS, JMC, LM, and DS have contributed to the design, acquisition of data, data analysis and interpretation, and manuscript preparation and review. All authors read and approved the final version of the manuscript.

\section{Funding}

Alliance Bristol-Myers Squibb/Pfizer Spain supported this study. However, this company has not participated in data collection and analysis and interpretation of the data, and the preparation of the manuscript.

\section{Availability of data and materials}

The datasets used and/or analyzed during the current study are available from the corresponding author on reasonable request.

\section{Declarations}

\section{Ethics approval and consent to participate}

The study was approved by the Independent Ethics Committee of La Princesa University Hospital (Madrid, Spain), and written informed consent was obtained from all patients before they were included in the study.

\section{Consent for publication}

Not applicable as this manuscript does not contain any person's data.

\section{Competing interests}

C. Suarez has received speaker honoraria or advisory board fees from BMS/ Pfizer, Bayer, and Daiichi Sankyo. J.M. Cepeda has received speaker honoraria and advisory board fees from BMS/Pfizer, Bayer, and Daiichi Sankyo. L. Manzano has received speaker honoraria or advisory board fees from BMS/Pfizer, Bayer, Boehringer Ingelheim and Daiichi Sankyo. D. Sánchez has received payments from collaborations with Bayer, BMS/Pfizer, Boehringer Ingelheim and Daiichi Sankyo. J.M. Mostaza declares that he does not have any conflict of interest.

\section{Author details}

'Department of Internal Medicine, Hospital Carlos III, Calle Sinesio Delgado, 10, 28029 Madrid, Spain. ${ }^{2}$ Department of Internal Medicine, Hospital Universitario de La Princesa, Madrid, Spain. ${ }^{3}$ Department of Internal Medicine, Hospital Vega Baja, Orihuela, Alicante, Spain. ${ }^{4}$ Department of Internal Medicine, Hospital Ramón Y Cajal, Universidad de Alcalá, Ramón Y Cajal Health Research Institute (IRYCIS), Madrid, Spain. ${ }^{5}$ Department of Internal Medicine, Hospital Nuestra Señora De Sonsoles, Ávila, Spain. ${ }^{6}$ Hospital Clínico Universitario Virgen de La Victoria, Málaga, Spain. ${ }^{7}$ Hospital Comarcal Infanta Margarita, Córdoba, Spain. ${ }^{8}$ Complejo Hospitalario Regional Reina Sofía, Córdoba, Spain. ${ }^{9}$ Complejo Hospitalario Regional de Málaga (Hospital Carlos Haya), Málaga, Spain. ${ }^{10}$ Complejo Hospitalario de Poniente, El Ejido, Almería, Spain. ${ }^{11}$ Hospital Torrecárdenas, Almeria, Spain. ${ }^{12}$ Hospital Universitario Virgen de Las Nieves, Granada, Spain. ${ }^{13}$ Hospital Virgen de Las Montañas, Cádiz, Spain. ${ }^{14}$ Complejo Hospitalario Virgen Macarena, Sevilla, Spain. ${ }^{15}$ Hospital Quironsalud Sagrado Corazón, Sevilla, Spain. ${ }^{16}$ Hospital Infanta Luisa, Sevilla, Spain. ${ }^{17}$ Hospital de Alcañiz, Teruel, Spain. ${ }^{18}$ Hospital Royo Villanova, Zaragoza, Spain. ${ }^{19}$ Hospital Universitario Miguel Servet, Zaragoza, Spain. ${ }^{20}$ Hospital San Agustín, Avilés, Asturias, Spain. ${ }^{21}$ Hospital de Cabueñes, Gijón, Spain. ${ }^{22}$ Hospital Comarcal de Inca, Islas Baleares, Spain. ${ }^{23}$ Hospital Universitario de Canarias, Santa Cruz de Tenerife, Spain. ${ }^{24}$ Hospital Universitario de Gran Canaria Doctor Negrín, Las 
Palmas de Gran Canaria, Las Palmas, Spain. ${ }^{25}$ Hospital Universitario Marqués de Valdecilla, Santander, Spain. ${ }^{26}$ Hospital Comarcal de Laredo, Laredo, Spain. ${ }^{27}$ Hospital Sierrallana, Torrelavega, Cantabria, Spain. ${ }^{28}$ Complejo Asistencial Universitario de León, León, Spain. ${ }^{29}$ Complejo Asistencial Universitario de Burgos, Burgos, Spain. ${ }^{30}$ Complejo Asistencial de Zamora, Zamora, Spain. ${ }^{31}$ Hospital Universitario Rio Hortega, Valladolid, Spain. ${ }^{32}$ Complejo Asistencial de Ávila, Ávila, Spain. ${ }^{33}$ Complejo Asistencial de Segovia, Segovia, Spain. ${ }^{34} \mathrm{Hos}-$ pital Santa Bárbara, Ciudad Real, Spain. ${ }^{35}$ Hospital Nuestra Señora del Prado, Talavera de La Reina, Toledo, Spain. ${ }^{36} \mathrm{Hospital}$ Virgen de La Salud, Toledo, Spain. ${ }^{37}$ Hospital Virgen de La Luz, Cuenca, Spain. ${ }^{38}$ Hospital de La Santa Creu I Sant Pau, Barcelona, Spain. ${ }^{39}$ Hospital Cima Sanitas, Barcelona, Spain. ${ }^{40} \mathrm{Hos}-$ pital Universitari Joan XXIII, Tarragona, Spain. ${ }^{41}$ Hospital Universitari de Sant Joan de Reus, Tarragona, Spain. ${ }^{42}$ Hospital Clinic I Provincial, Barcelona, Spain. ${ }^{43}$ Hospital Universitari Vall D'Hebron, Barcelona, Spain. ${ }^{44}$ Parc Sanitari Sant Joan de Deu, Barcelona, Spain. ${ }^{45}$ Hospital Universitari de Bellvitge, Bellvitge Biomedical Research Institute (IDIBELL), L'Hospitalet de Llobregat, Barcelona, Spain. ${ }^{46}$ Hospital de Sant Joan Despí Moisés Broggi, Sant Joan Despí, Barcelona, Spain. ${ }^{47}$ Hospital Universitari de Girona Dr. Josep Trueta, Girona, Spain. ${ }^{48}$ Hospital Quirón Salud del Vallés, Sabadell, Barcelona, Spain. ${ }^{49} \mathrm{Hospital}$ Santa María, Alcalá de Henares, Madrid, Spain. ${ }^{50}$ Hospital Mutua de Terrassa, Terrassa, Barcelona, Spain. ${ }^{51}$ Hospital de Mataró, Mataró, Barcelona, Spain. ${ }^{52}$ Hospital de Mollet, Mollet del Vallès, Barcelona, Spain. ${ }^{53}$ Hospital del Vendrell, El Vendrell, Tarragona, Spain. ${ }^{54} \mathrm{Hospital}$ Perpetuo Socorro, Badajoz, Spain. ${ }^{55} \mathrm{Complejo}$ Hospitalario Llerena-Zafra, Llerena, Badajoz, Spain. ${ }^{56}$ Complejo Hospitalario de Cáceres, Cáceres, Spain. ${ }^{57}$ Hospital Virgen del Puerto, Plasencia, Cáceres, Spain. ${ }^{58}$ Hospital Infanta Cristina, Badajoz, Spain. ${ }^{59}$ Complexo Hospitalario Universitario Arquitecto Marcide-Novoa Santos, Ferrol, A Coruña, Spain. ${ }^{60} \mathrm{Complexo}$ Hospitalario Universitario de Ourense, Ourense, Spain. ${ }^{61} \mathrm{Com}-$ plexo Hospitalario Universitario de Pontevedra, Pontevedra, Spain. ${ }^{62}$ Hospital de Povisa, Vigo, Pontevedra, Spain. ${ }^{63}$ Complejo Hospitalario Universitario de Santiago, Santiago de Compostela, A Coruña, Spain. ${ }^{64}$ Complejo Hospitalario de Vigo, Vigo, Pontevedra, Spain. ${ }^{65}$ Complejo Hospital San Pedro, Logroño, La Rioja, Spain. ${ }^{66}$ Fundación Hospital Calahorra, Calahorra, La Rioja, Spain. ${ }^{67}$ Hospital Puerta de Hierro, Madrid, Spain. ${ }^{68} \mathrm{Hospital}$ Universitario Infanta Sofía, San Sebastián de Los Reyes, Madrid, Spain. ${ }^{69}$ Hospital Clínico San Carlos, Madrid, Spain. ${ }^{70}$ Hospital Universitario HM Montepríncipe, Boadilla del Monte, Madrid, Spain. ${ }^{71}$ Hospital Universitario 12 de octubre, Madrid, Spain. ${ }^{72}$ Hospital Universitario Príncipe de Asturias, Alcalá de Henares, Madrid, Spain. ${ }^{73}$ Hospital Universitario de Getafe, Getafe, Madrid, Spain. ${ }^{74}$ Hospital Universitario del Henares, Coslada, Madrid, Spain. ${ }^{75}$ Hospital Universitario Infanta Cristina, Parla, Madrid, Spain. ${ }^{76}$ Hospital Universitario Fundación Alcorcón, Alcorcón, Madrid, Spain. ${ }^{77}$ Hospital Universitario Infanta Leonor, Madrid, Spain. ${ }^{78}$ Hospitalario General Universitario Gregorio Marañón, Madrid, Spain. ${ }^{79}$ Hospital de Fuenlabrada, Fuenlabrada, Madrid, Spain. ${ }^{80}$ Hospital Virgen de La Arrixaca, El Palmar, Murcia, Spain. ${ }^{81}$ Hospital Santa Lucía, Cartagena, Murcia, Spain. ${ }^{82}$ Complejo Hospitalario de Navarra, Pamplona, Navarra, Spain. ${ }^{83}$ Policlínica San José, Vitoria, Álava, Spain. ${ }^{84}$ Hospital Santa Marina, Bilbao, Vizcaya, Spain. ${ }^{85}$ Clínica Virgen Blanca, Bilbao, Vizcaya, Spain. ${ }^{86} \mathrm{Hospital}$ Gral. Castellón, Castellón de La Plana, Castellón, Spain. ${ }^{87}$ Hospital Doctor Peset, Valencia, Spain. ${ }^{88} \mathrm{Hospital}$ La $\mathrm{Fe}$, Valencia, Spain. ${ }^{89} \mathrm{Hospital}$ Universitario San Juan, Alicante, Spain. ${ }^{90} \mathrm{Hos}-$ pital General de Elche. Elche, Alicante, Spain. ${ }^{91}$ Hospital del Vinalopó, Elche, Alicante, Spain.

Received: 21 September 2020 Accepted: 15 April 2021 Published online: 09 August 2021

\section{References}

1. Barrios V, Calderon A, Escobar C, de la Figuera M. Patients with atrial fibrillation in a primary care setting: Val-FAAP study. Rev Esp Cardiol (Engl Ed). 2012;65:47-53.

2. Lip GY. Stroke in atrial fibrillation: epidemiology and thromboprophylaxis. J Thromb Haemost. 2011;9(Suppl 1):344-51.

3. Lip GY, Lim HS. Atrial fibrillation and stroke prevention. Lancet Neurol. 2007;6:981-93.

4. Wolf PA, Abbott RD, Kannel WB. Atrial fibrillation as an independent risk factor for stroke: the Framingham study. Stroke. 1991;22:983-8.

5. Steger C, Pratter A, Martinek-Bregel M, Avanzini M, Valentin A, Slany J, et al. Stroke patients with atrial fibrillation have a worse prognosis than patients without: data from the Austrian Stroke registry. Eur Heart J. 2004;25:1734-40.

6. Lakshminarayan K, Solid CA, Collins AJ, Anderson DC, Herzog CA. Atrial fibrillation and stroke in the general medicare population: a 10-year perspective (1992 to 2002). Stroke. 2006;37:1969-74.

7. Wolf PA, Abbott RD, Kannel WB. Atrial fibrillation: a major contributor to stroke in the elderly. The Framingham Study. Arch Intern Med. 1987;147:1561-4

8. Lip GY, Nieuwlaat R, Pisters R, Lane DA, Crijns HJ. Refining clinical risk stratification for predicting stroke and thromboembolism in atrial fibrillation using a novel risk factor-based approach: the euro heart survey on atrial fibrillation. Chest. 2010;137:263-72.

9. Hart RG, Pearce LA, Aguilar MI. Meta-analysis: antithrombotic therapy to prevent stroke in patients who have nonvalvular atrial fibrillation. Ann Intern Med. 2007;146:857-67.

10. Mekaj YH, Mekaj AY, Duci SB, Miftari El. New oral anticoagulants: their advantages and disadvantages compared with vitamin K antagonists in the prevention and treatment of patients with thromboembolic events. Ther Clin Risk Manag. 2015;11:967-77.

11. Connolly SJ, Eikelboom J, Joyner C, Diener HC, Hart R, Golitsyn $\mathrm{S}$, et al. Apixaban in patients with atrial fibrillation. N Engl J Med. 2011;364:806-17.

12. Connolly SJ, Ezekowitz MD, Yusuf S, Eikelboom J, Oldgren J, Parekh A, et al. Dabigatran versus warfarin in patients with atrial fibrillation. N Engl J Med. 2009:361:1139-51.

13. Patel MR, Mahaffey KW, Garg J, Pan G, Singer DE, Hacke W, et al. Rivaroxaban versus warfarin in nonvalvular atrial fibrillation. $N$ Engl I Med. 2011;365:883-91.

14. Ruff CT, Giugliano RP, Braunwald E, Hoffman EB, Deenadayalu N, Ezekowitz MD, et al. Comparison of the efficacy and safety of new oral anticoagulants with warfarin in patients with atrial fibrillation: a meta-analysis of randomised trials. Lancet. 2014;383:955-62.

15. Giugliano RP, Ruff CT, Braunwald E, Murphy SA, Wiviott SD, Halperin JL, et al. Edoxaban versus warfarin in patients with atrial fibrillation. $N$ Engl J Med. 2013;369:2093-104.

16. Kirchhof P, Benussi S, Kotecha D, Ahlsson A, Atar D, Casadei B, et al. 2016 ESC Guidelines for the management of atrial fibrillation developed in collaboration with EACTS. Eur Heart J. 2016;37:2893-962.

17. Steffel J, Verhamme P, Potpara TS, Albaladejo P, Antz M, Desteghe L, et al. The 2018 European Heart Rhythm Association Practical Guide on the use of non-vitamin K antagonist oral anticoagulants in patients with atrial fibrillation. Eur Heart J. 2018;39:1330-93.

18. Le Heuzey JY, Ammentorp B, Darius H, De Caterina R, Schilling RJ, Schmitt $J$, et al. Differences among western European countries in anticoagulation management of atrial fibrillation. Data from the PREFER IN AF registry. Thromb Haemost. 2014;111:833-41.

19. Wilke T, Groth A, Mueller S, Pfannkuche M, Verheyen F, Linder R, et al. Oral anticoagulation use by patients with atrial fibrillation in Germany Adherence to guidelines, causes of anticoagulation under-use and its clinical outcomes, based on claims-data of 183,448 patients. Thromb Haemost. 2012;107:1053-65.

20. Sharma M, Cornelius VR, Patel JP, Davies JG, Molokhia M. Efficacy and harms of direct oral anticoagulants in the elderly for stroke prevention in atrial fibrillation and secondary prevention of venous thromboembolism: systematic review and meta-analysis. Circulation. 2015;132:194-204.

21. Denoel P, Vanderstraeten J, Mols P, Pepersack T. Could some geriatric characteristics hinder the prescription of anticoagulants in atrial fibrillation in the elderly? J Aging Res. 2014;2014:693740.

22. Martinez de la Iglesia J, Duenas Herrero R, Onis Vilches MC, Aguado Taberne C, Albert Colomer C, Luque Luque R. Spanish language adaptation and validation of the Pfeiffer's questionnaire (SPMSQ) to detect cognitive deterioration in people over 65 years of age [Adaptacion y validacion al castellano del cuestionario de Pfeiffer (SPMSQ) para detectar la existencia de deterioro cognitivo en personas mayores de 65 anos]. Med Clin (Barc). 2001;117:129-34.

23. Pfeiffer E. A short portable mental status questionnaire for the assessment of organic brain deficit in elderly patients. J Am Geriatr Soc. 1975;23:433-41.

24. Mahoney FI, Barthel DW. Functional evaluation: the barthel index. Md State Med J. 1965;14:61-5. 
25. Charlson ME, Pompei P, Ales KL, Mackenzie CR. A new method of classifying prognostic comorbidity in longitudinal studies: development and validation. J Chronic Dis. 1987:40:373-83.

26. Bernabeu-Wittel M, Ollero-Baturone M, Moreno-Gavino L, Baron-Franco B, Fuertes A, Murcia-Zaragoza J, et al. Development of a new predictive model for polypathological patients. The PROFUND index. Eur J Intern Med. 2011;22:311-7.

27. Pisters R, Lane DA, Nieuwlaat R, de Vos CB, Crijns HJ, Lip GY. A novel user-friendly score (HAS-BLED) to assess 1-year risk of major bleeding in patients with atrial fibrillation: the Euro Heart Survey. Chest. 2010;138:1093-100.

28. Hylek EM, D'Antonio J, Evans-Molina C, Shea C, Henault LE, Regan S. Translating the results of randomized trials into clinical practice: the challenge of warfarin candidacy among hospitalized elderly patients with atrial fibrillation. Stroke. 2006;37:1075-80.

29. Pugh D, Pugh J, Mead GE. Attitudes of physicians regarding anticoagulation for atrial fibrillation: a systematic review. Age Ageing. 2011:40:675-83.

30. Gage BF, Birman-Deych E, Kerzner R, Radford MJ, Nilasena DS, Rich MW. Incidence of intracranial hemorrhage in patients with atrial fibrillation who are prone to fall. Am J Med. 2005;118:612-7.

31. Garwood CL, Corbett TL. Use of anticoagulation in elderly patients with atrial fibrillation who are at risk for falls. Ann Pharmacother 2008;42:523-32.

32. Singer DE, Chang Y, Fang MC, Borowsky LH, Pomernacki NK, Udaltsova $\mathrm{N}$, et al. The net clinical benefit of warfarin anticoagulation in atrial fibrillation. Ann Intern Med. 2009;151:297-305.

33. Hernández VSJ, Mazoteras V, López MT. Underuse of oral anticoagulation in octogenarian patient with atrial fibrillation: a perspective from real clinical practice. Rev Colom Cardiol. 2015;22:231-4.

34. Bai Y, Guo SD, Deng H, Shantsila A, Fauchier L, Ma CS, et al. Effectiveness and safety of oral anticoagulants in older patients with atrial fibrillation: a systematic review and meta-regression analysis. Age Ageing. 2018;47:9-17.

35. Huisman MV, Rothman KJ, Paquette M, Teutsch C, Diener HC, Dubner SJ, et al. The changing landscape for stroke prevention in AF: findings from the GLORIA-AF registry phase 2. J Am Coll Cardiol. 2017;69:777-85.

36. Esposti LD, Briere JB, Bowrin K, Diego S, Perrone V, Pasquale GD. Antithrombotic treatment patterns in patients with atrial fibrillation in Italy pre- and post-DOACs: the REPAIR study. Future Cardiol. 2019;15:109-18.

37. Lacoin L, Lumley M, Ridha E, Pereira M, McDonald L, Ramagopalan S, et al. Evolving landscape of stroke prevention in atrial fibrillation within the UK between 2012 and 2016: a cross-sectional analysis study using CPRD. BMJ Open. 2017;7:e015363.

38. Gullon A, Suarez C, Diez-Manglano J, Formiga F, Cepeda JM, Pose A, et al. Antithrombotic treatment and characteristics of elderly patients with non-valvular atrial fibrillation hospitalized at Internal Medicine departments. NONAVASC registry [Caracteristicas y tratamiento antitrombotico de los pacientes ancianos con fibrilacion auricular no valvular hospitalizados en Medicina Interna. Registro NONAVASC]. Med Clin (Barc). 2017;148:204-10.

39. Poli D, Antonucci E, Grifoni E, Abbate R, Gensini GF, Prisco D. Bleeding risk during oral anticoagulation in atrial fibrillation patients older than 80 years. J Am Coll Cardiol. 2009;54:999-1002.

40. Friberg L, Rosenqvist M, Lip GY. Evaluation of risk stratification schemes for ischaemic stroke and bleeding in 182678 patients with atrial fibrillation: the Swedish Atrial Fibrillation cohort study. Eur Heart J. 2012;33:1500-10.

41. Lip GY, Lane DA. Assessing bleeding risk in atrial fibrillation with the HAS-BLED and ORBIT scores: clinical application requires focus on the reversible bleeding risk factors. Eur Heart J. 2015;36:3265-7.

42. Mant J, Hobbs FD, Fletcher K, Roalfe A, Fitzmaurice D, Lip GY, et al. Warfarin versus aspirin for stroke prevention in an elderly community population with atrial fibrillation (the Birmingham Atrial Fibrillation Treatment of the Aged Study, BAFTA): a randomised controlled trial. Lancet. 2007;370:493-503.
43. Polo Garcia J, Vargas Ortega D, Formiga F, Unzueta I, Fernandez de Cabo S, Chaves J. Profiling of patients with non-valvular atrial fibrillation and moderate-to-high risk of stroke not receiving oral anticoagulation in Spain. Semergen. 2018.

44. Lopez Soto A, Formiga F, Bosch X, Garcia AJ. Prevalence of atrial fibrillation and related factors in hospitalized old patients: ESFINGE study [Prevalencia de la fibrilacion auricular y factores relacionados en pacientes ancianos hospitalizados: estudio ESFINGE]. Med Clin (Barc). 2012;138:231-7.

45. Lobos-Bejarano JM, del Castillo-Rodriguez JC, Mena-Gonzalez A, Aleman-Sanchez JJ, Cabrera de Leon A, Baron-Esquivias G, et al. Patients' characteristics and clinical management of atrial fibrillation in primary healthcare in Spain: FIATE Study [Caracteristicas de los pacientes y abordaje terapeutico de la fibrilacion auricular en atencion primaria en Espana: Estudio FIATE]. Med Clin (Barc). 2013;141:279-86.

46. Van Staa TP, Setakis E, Di Tanna GL, Lane DA, Lip GY. A comparison of risk stratification schemes for stroke in 79,884 atrial fibrillation patients in general practice. J Thromb Haemost. 2011;9:39-48.

47. Boriani G, Laroche C, Diemberger I, Fantecchi E, Popescu MI, Rasmussen $\mathrm{LH}$, et al. 'Real-world' management and outcomes of patients with paroxysmal vs. non-paroxysmal atrial fibrillation in Europe: the EURObservational Research Programme-Atrial Fibrillation (EORP-AF) General Pilot Registry. Europace. 2016;18:648-57.

48. Ganesan AN, Chew DP, Hartshorne T, Selvanayagam JB, Aylward PE, Sanders $P$, et al. The impact of atrial fibrillation type on the risk of thromboembolism, mortality, and bleeding: a systematic review and meta-analysis. Eur Heart J. 2016;37:1591-602.

49. Rodriguez-Bernal CL, Hurtado I, Garcia-Sempere A, Peiro S, SanfelixGimeno G. Oral anticoagulants initiation in patients with atrial fibrillation: real-world data from a population-based cohort. Front Pharmacol. 2017;8:63.

50. Moreno-Arribas J, Bertomeu-Gonzalez V, Anguita-Sanchez M, Cequier A, Muniz J, Castillo J, et al. Choice of new oral anticoagulant agents versus vitamin Kantagonists in atrial fibrillation: FANTASIIA study. J CardiovasC Pharmacol Ther. 2016;21:150-6.

51. Barrios V, Escobar C, Lobos JM, Polo J, Vargas D. Use of non-vitamin K antagonist oral anticoagulants in Primary Care: ACTUA study [Uso de los anticoagulantes orales de accion directa en atencion primaria: Estudio ACTUA]. SEMERGEN. 2017;43:477-85.

52. Agencia Española de Medicamento y Productos Sanitarios (AEMPS). Criterios y recomendaciones para el uso de nuevos anticoagulantes orales (NACO) en la prevención del ictus y la embolia sistémica en pacientes con fibrilación auricular no valvular. Informe de Posicionamiento Terapéutico UTN4/23122013. 2016. Available from: https://www.aemps.gob. es/medicamentosUsoHumano/informesPublicos/home.htm\#anticoagul antes-orales.

53. Olesen JB, Sorensen R, Hansen ML, Lamberts M, Weeke P, Mikkelsen AP, et al. Non-vitamin K antagonist oral anticoagulation agents in anticoagulant naive atrial fibrillation patients: Danish nationwide descriptive data 2011-2013. Europace. 2015;17:187-93.

54. Urbaniak AM, Strom BO, Krontveit R, Svanqvist KH. Prescription patterns of non-vitamin K oral anticoagulants across indications and factors associated with their increased prescribing in atrial fibrillation between 2012-2015: a study from the norwegian prescription database. Drugs Aging. 2017;34:635-45.

55. Steinberg BA, Shrader P, Thomas L, Ansell J, Fonarow GC, Gersh BJ, et al. Factors associated with non-vitamin $\mathrm{K}$ antagonist oral anticoagulants for stroke prevention in patients with new-onset atrial fibrillation: Results from the Outcomes Registry for Better Informed Treatment of Atrial Fibrillation II (ORBIT-AF II). Am Heart J. 2017;189:40-7.

56. Ho P, Brooy BL, Hayes L, Lim WK. Direct oral anticoagulants in frail older adults: a geriatric perspective. Semin Thromb Hemost. 2015;41:389-94.

57. Pather M. The prevalence of renal impairment in the elderly hospitalized population. Int J Gen Med. 2009;2:117-9.

\section{Publisher's Note}

Springer Nature remains neutral with regard to jurisdictional claims in published maps and institutional affiliations. 